\title{
The impact of collaborative internet platforms on cultural tourism
}

\author{
Marta-Christina SUCIU \\ Bucharest University of Economic Studies, Bucharest Romania \\ Christina.suciu@economie.ase.ro \\ Mircea-Ovidiu MITUCĂ \\ Bucharest University of Economic Studies, Bucharest Romania \\ mircea.mituca@gmail.com
}

\begin{abstract}
Cultural tourism has seen a growing trend in the past years and beside the vast financial advantages that are brought to the host country, it must also cope with the responsibility of educating individuals in an efficient manner. This paper proposes to analyse to what extent collaborative internet based platforms can influence cultural tourism. As it is a complex relationship, we must evaluate and interpret the results of this study from different perspectives. The most appropriate example of cultural tourism in Romania is the Museum. In the past years, the concept of cultural hub became more prominent in our country and by becoming its main representative, mainly due to its intelligent use of technology and internet platforms, the Museum can actively contribute to civic education and to the increase of social cohesion - these are deficient aspects whose improvement should concern as many responsible factors in society as possible.
\end{abstract}

Keywords: Cultural tourism, Museums, Visitors, Online information, World travel.

\section{Introduction}

Nowadays, collaborative internet platforms play an important role in our daily activities. We organize ourselves and our ventures through them, while they also offer a place to debate, analyse and reflect on any idea that we might have. Having this supposedly virtual infinite space of reality at our disposal, people tend to make a shift from their traditional lives.

When talking about the impact of collaborative internet platforms have, one important sector of activity that might be affected is cultural tourism. Beside many other advantages that it offered, social media made remote almost "unknown" places into quite popular, if not even famous and attractive places in an instant. According to the World Tourism Organization, in 2018, the number of international tourist arrivals worldwide reached 1.4 billion, fact that had been predicted two years before. In the Travel \& Tourism Competitiveness Report published by the World Economic Forum in 2019 international experts mention that: "2018 also marked the seventh year in a row where the growth in tourism exports (+4\%) exceeded the growth in merchandise exports $(+3 \%)$. Given this rapid pace of growth, the prediction that international arrivals will reach 1.8 billion by 2030 may be conservative." (The Travel \& Tourism Competitiveness Report 2019, 2019, p. 5). In the next paragraphs, we will also highlight some of the disadvantages social media might bring to cultural tourism, along with the large amount of advantages.

Since the inception of Internet, people realised its potential to facilitate easy communication between peers from one place of the earth to another. But few predicted the actual impact that Internet and its by-products like social media platforms would eventually have on humanity. Reputation, family statements, official way of communication for different institutions are just a few ideas that were usually connected to the real life, where people met in person "face to face" to discuss. Now each person that has a smartphone and Internet connection might potentially be actively involved in this new trend. 
Artists of all types, scientists and a multitude of public figures owe their massive overnight success to the increasing visibility collaborative internet platforms offered them. Twenty years ago, things would have been more difficult, even though potential existed also back then. The difference might be the number of people that have access to Internet and all the amazing information that are available nowadays making it sometimes difficult for us to select the relevant type of information for our professional life. In order to better understand how they influence each other, we have to analyse their complex and dynamic interrelationship from different angles.

On one hand, from an economical perspective, collaborative internet platforms enhanced the efficiency, effectiveness and profitability of any cultural institution or enterprise. The number of people that find new interesting places to visit with the help of other individuals that share their experiences online is growing exponentially. Secondary theatres that are not exactly in the city centre, vernissages of young artists and even antiquity selling boutiques have benefited from a big financial influx through the help of more curious tourists that have chosen to share their experiences online.

On the other hand, while witnessing the benefits it brings to more unfamiliar places, it had brought even more attention to places that were already crowded. Louvre, Bolshoi or Rembrandt Museums are full of people every day and sometimes, in different periods of the year, you need a booking to visit them. One who might not understand the noise behind the Scream of Edvard Munch, but as long as a photo is taken with it, the tourist is happy to have something to post himself on social media.

\section{Brief literature review}

Tourism became a critically important part of host countries throughout the years contributing a lot to the growing wealth for their economies. Driven by a strong regional and global economy, advances in technology, growth of the middle class in the emerging countries and affordable travel costs, international tourist arrivals grew by an average rate of 5\% in 2019 and reached the 1.4 billion USD? In the same time, export earnings generated by tourism have grown to USD 1.7 trillion. (United Nations World Tourism Organization, 2019). This confirms that tourism sector has an important influence on the development and economic growth of a region or country (in Figure 1 there are illustrated the top 10 destinations receiving $40 \%$ of worldwide arrivals), by generating new $\&$ better paid jobs and by attracting entrepreneurs and 


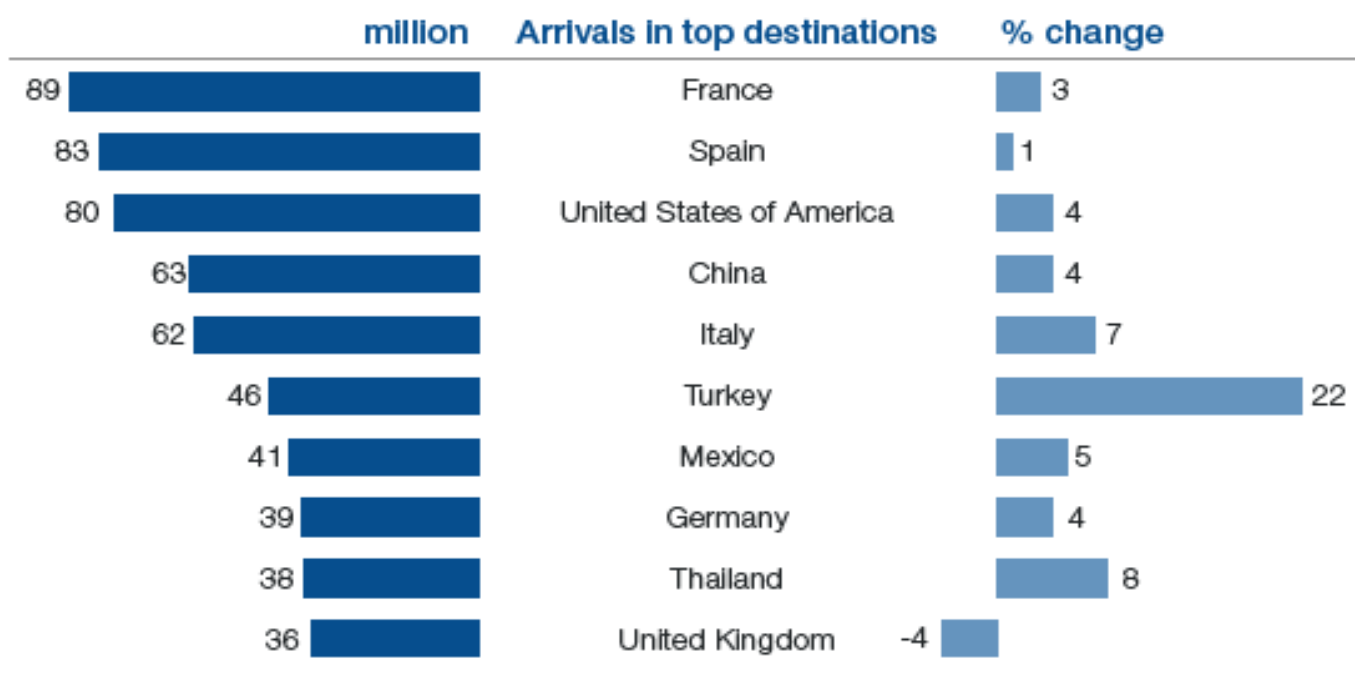

PICBE | 1137

Figure 1-Top ten destinations by international tourist arrivals, 2018.

Source: World Tourism Organization (UNWTO).

Cultural Tourism is a sub-category of tourism that cumulates the activities of discovering the cultural attractions one particular place has with understanding its value in a national and international context. Usually, this form of tourism satisfies the need of people to learn something when they visit.

Operas, Theatres, Museums and also old settlements are places that one individual might visit in a cultural trip. The whole idea behind learning is also to understand: the different culture, architecture, art, the way of living and how society works in different part of the world. It is one of the fastest growing forms of tourism, and it directly benefits from the widespread of Internet. In Figure 2 we highlight that the evolution of revenues from visitor spending has a faster growing rate than the world economy.

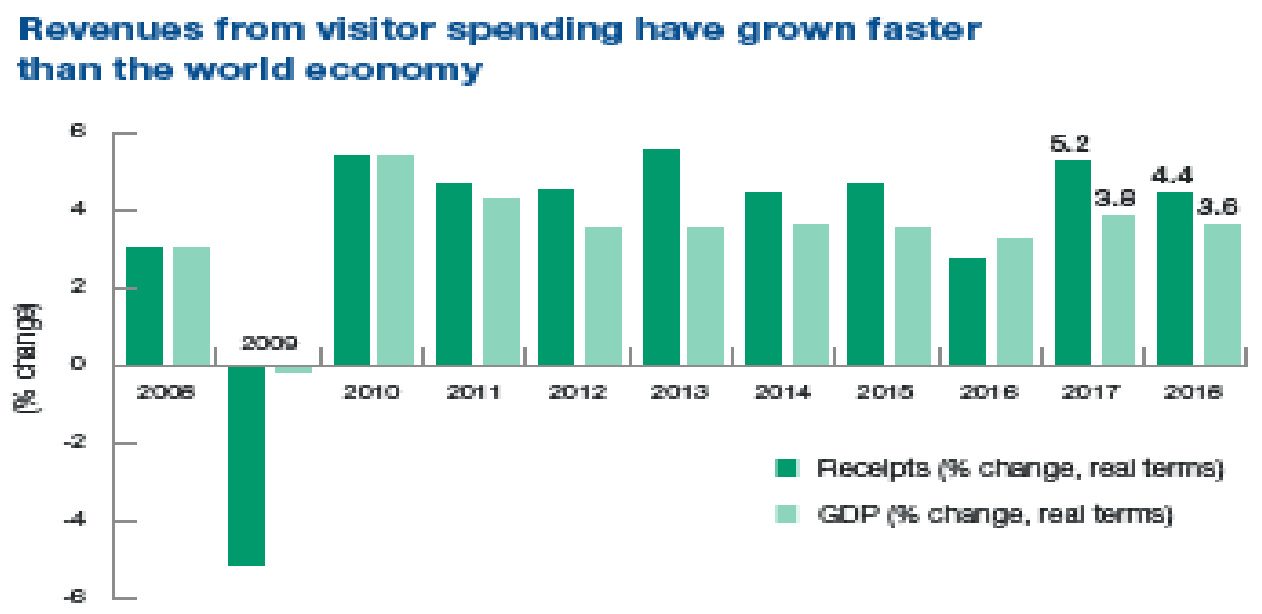

Figure 2-International tourism receipts and world GDP (\% change).2019.

Source: World Tourism Organization (UNTWO). 
Zurab Pololikashvili, the Secretary-General of the World Tourism Organization (UNWTO) argues that: "Digitalization, innovation, greater accessibility and societal changes are expected to continue shaping our sector. Both destinations and companies will need to adapt to remain competitive, while at the same time embracing tourism as a means of achieving the Sustainable Development Goals and building a better future for all" (World Tourism Organization, 2019, p. 2). This quotation seems to confirm the trend of regulating the sustainability of tourism in the world.

\section{Romania - Italy. A comparative analyse based on the Travel \& Tourism competitiveness index}

As we had mentioned before the World Economic Forum published in 2019 the Travel and Tourism Competitiveness Report. It looks for the sustainable development of travel and tourism in 140 countries in 2018 . This report analyses and highlights the strong points of each economy and it is used as a standard point of reference for any stakeholder interested in the T\&T (Travel \& Tourism) sector. By analysing the performance of countries from a regional and local perspective, one may find a legal gap that can be easily filled with the corresponding policies and/or find infrastructure management best practices that might positively influence the tourism demand. During the last four years, T\&T competitiveness continues to improve worldwide and international experts consider this to manifest as an ongoing trend.

The results from this report confirm the increase in the route capacity and the number of airlines providing services, mainly due to the air transport infrastructure. International openness is progressing, with lower-income economies leading the way. Travel has become safer and cheaper than the past decade, while digital connectivity between peers using the Internet enhanced the ability of economies to take advantage of the growing Travel and Tourism sector. On the other hand we might identify a potential negative perspective in the future: the increasing growth of demand for transportation services might surpass the infrastructure development. In the face of growing tourists, natural reservations and cultural attractions must be protected by better regulated policies, in order for T\&T sector to become more sustainable \& competitive.

In the next paragraphs, by analysing the data from Travel \& Tourism Competitiveness Index 2019, we will perform a comparative analysis between tourism in Italy (ranked on the $8^{\text {th }}$ position) and correspondingly in Romania (placed on the $56^{\text {th }}$ position according to this benchmarking). In Figure 3 we present the Travel \& Tourism Competitiveness Index 2019 for Italy. 
Travel \& Tourism Competitiveness Index 2019 edition

\begin{tabular}{|c|c|c|}
\hline Key Indicators & \multicolumn{2}{|c|}{ Sources: World Tourlam Organization (UNWTO) and World Travel and Tourlam Coundil (WTTC) } \\
\hline Average receipts per arrival & $\begin{array}{l}\text { T\&T industry employment } \\
\% \text { of total }\end{array}$ & $\begin{array}{r}1,543,100 \text { jobs } \\
6.6 \%\end{array}$ \\
\hline 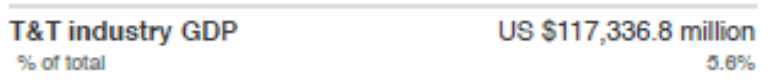 & T\&T industry Share of Employment & doyment \\
\hline
\end{tabular}

PICBE | 1139

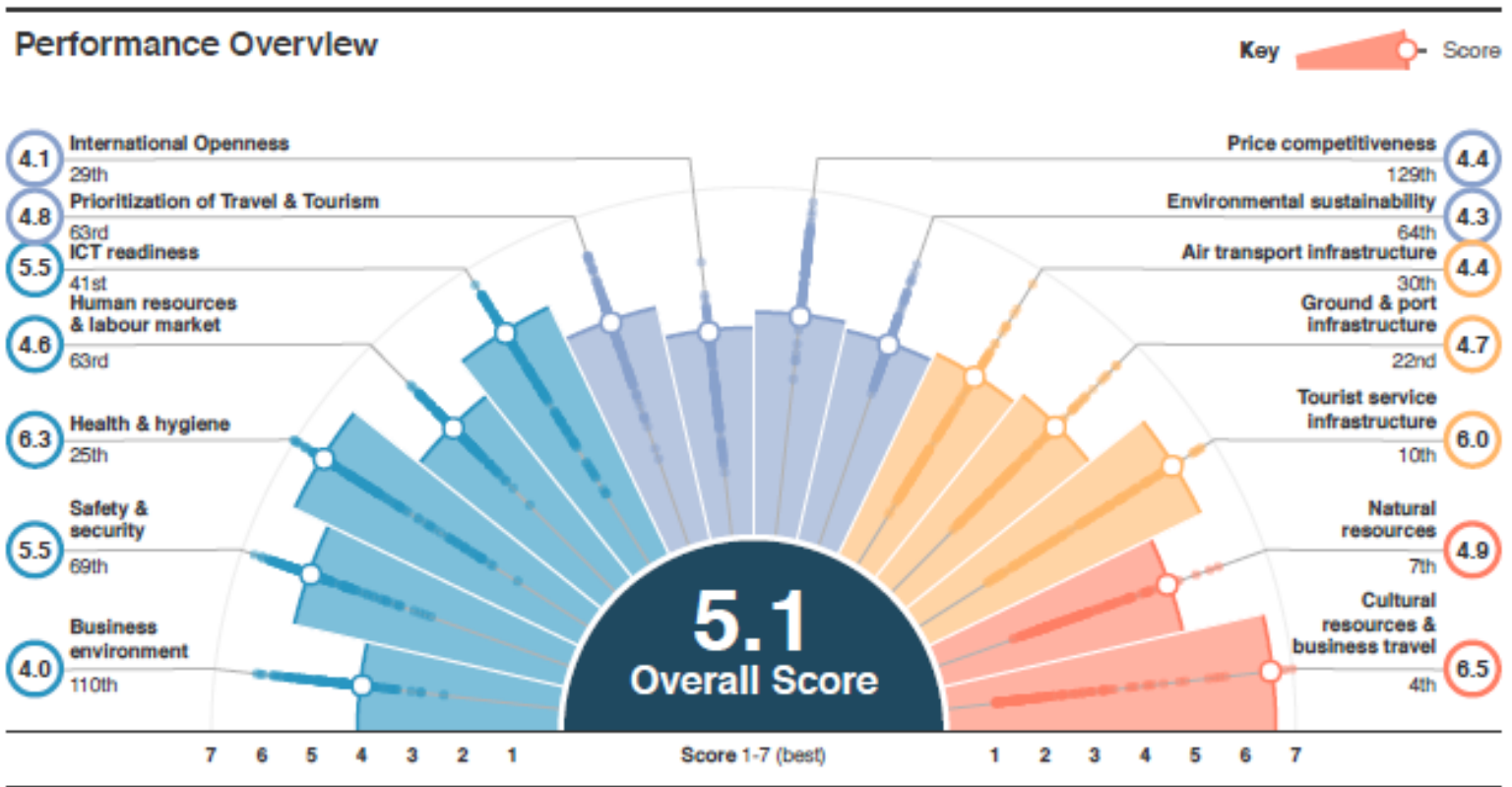

Figure 3- Italy. Travel \&Tourism Competitiveness Index 2019.

Source: World Economic Forum.

Firstly, we will analyse Italy and its data according to computed by the Travel \& Tourism Competitiveness Index 2019 published by the World Economic Forum. As we can see, the numbers are clearly in the advantage of the well-known leader in the tourism industry. Almost 60 million tourists spent almost 45 billion dollars in 2018. These vast amounts are giving the tourism industry a share of $5.6 \%$ in the total GDP of Italy.

While the country financially benefits a lot from the influx of tourists, its score is lower compared with countries like Spain or France that are dealing much better with some issues that Italy should also improve. Based on this comparative analysis we consider that the followng issues have to become the priorities for better managing tourism in Italy: price competitiveness, environmental sustainability, business environment and safety.

While there are many features in which it has to improve, Italy excels at many aspects. Tourist infrastructure is in the top 10 of the world, while natural resources put the country on the 7th place. But Italy does perform best at the dimenssion Cultural Resources \& Business Travel of the Travel \& Tourism Competitiveness Index 2019.

Having also a vast cultural heritage Italian are very proud of, the country managed to develop itself into one of the most popular destinations for cultural tourism. In Figure 4 we present the Travel \& Tourism Competitiveness Index 2019 for Romania. 


\section{Romania}

Travel \& Tourism Competitiveness Index 2019 edition

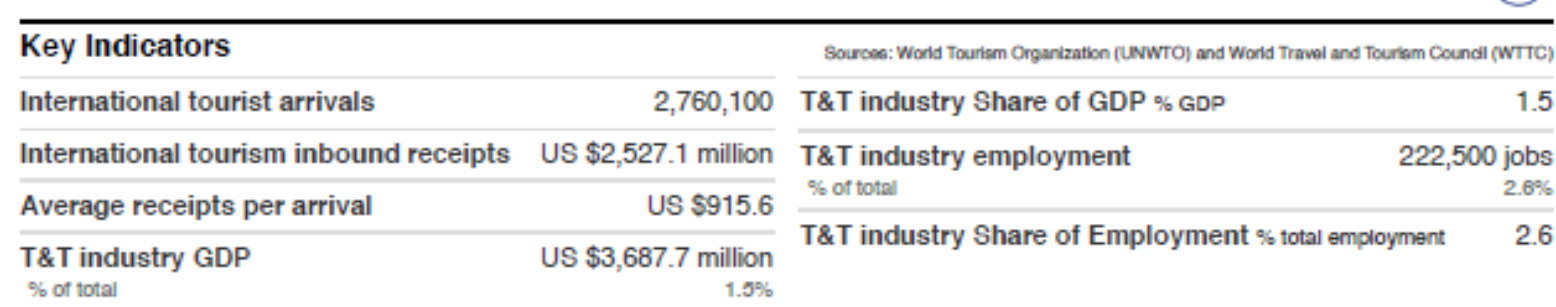

PICBE | 1140

\section{Performance Overvlew}

Key - Score

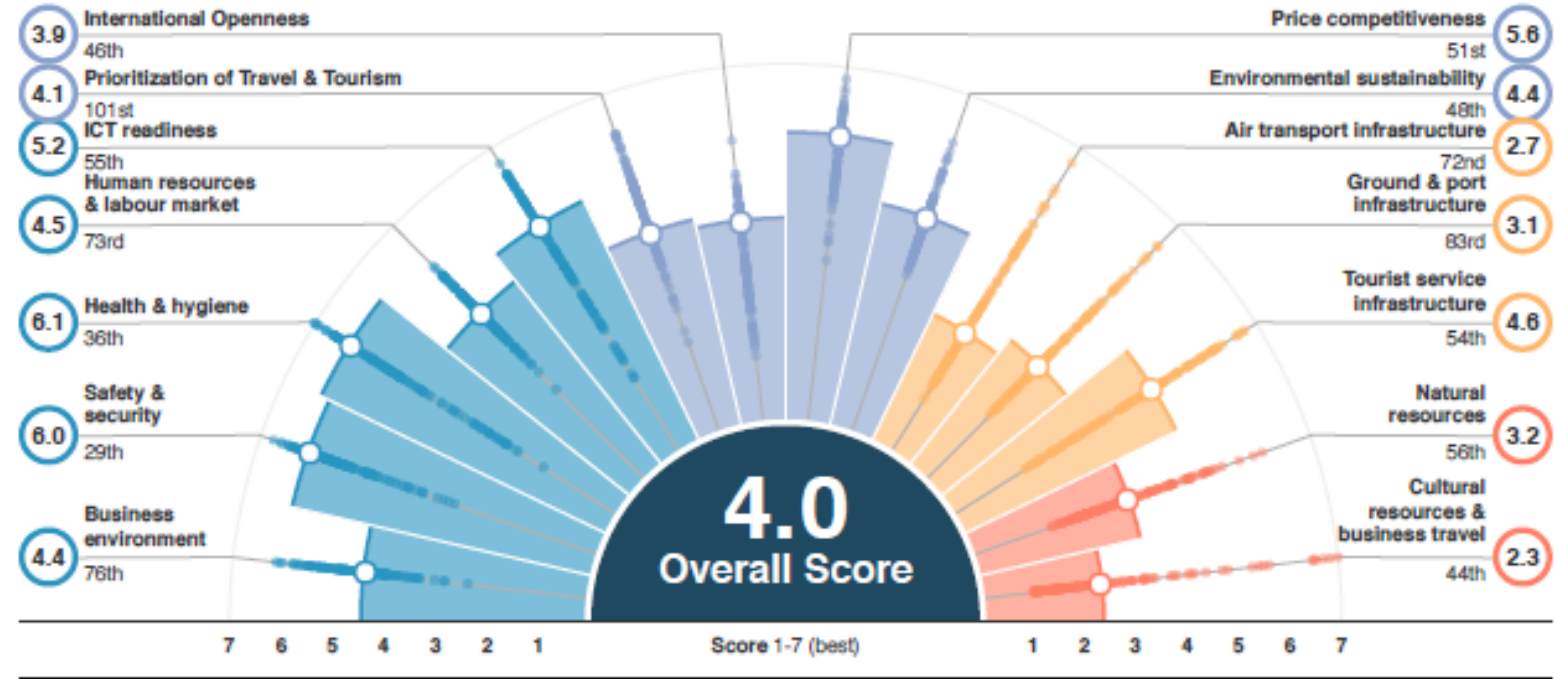

Figure 4-Romania.Travel \&Tourism Competitiveness Index 2019.

Source: World Economic Forum.

Regarding Romania, the country has almost 3 million visitors yearly, that contribute to the economy with 2.5 billion USD, consisting of $1.5 \%$ of the country GDP. These numbers bring our country on the 56th place in the world in terms of tourism, but Romania is considered among the emergent countries having a high potential for developing coultural tourism.

Based on the Travel \& Tourism Competitiveness Index 2019 we can see the following dimenisons where it is clear that Romania has to improve its performances: government agencies do not prioritize tourism as they should ( $101^{\text {st }}$ place), while the business environment is not yet very competitive $\left(76^{\text {th }}\right.$ place).

Romania seems to compensate with the fact that it is a relative safe place to visit, being ranked on the $29^{\text {th }}$ place. If tourism infrastructure will be improved, we might have a chance of raise our overall score on the Travel \& Tourism Competitiveness Index. With respect to the Cultural resources and business travel dimenision, Romania has a score of 2.3, which ranks Romania on the $44^{\text {th }}$ place. Based on this anlysis we can clearly state that in the case of Romania there is big room for important improvements.

\section{The museum as a potential cultural hub}


The purpose of a museum, regardless of its size, is to transmit a consistent impact message, whether it is philosophical, political, moral, historical or scientific. We cannot talk about the museum and its contribution if we do not debate about what has undergone a real development in recent years, mostly ITC technologies in terms of different smart phone applications. Applications such as Google Maps became real helping tools for different people who are using them as a guide to reach their destination. The accuracy with which it operates is high, while users always enjoy updated data due to satellites. Applications of this kind prove to be virtual guides, trying to replace the classic ones. Specialists that are researching the trends of the evolution of modern museums (Eid, 2015) consider that the transformation of museums into cultural hubs is a quite natural process within the technological and social progress, which covers the need to regain the public interest, proving to be very benefic stage not only from a cultural and educational point of view, but also from an economic and social one.

A cultural hub might be defined as a grouping of sites or cultural events that take place (usually) in one place, illustrated by museums, art galleries, creative spaces and theatres, which gather around them also secondary activities, including entertainment and commerce (Becut, 2018). Essentially, minimal infrastructure is needed to ensure an operational functionality of a cultural hub, and it might be seamlessly attached to all types of hubs through the features it shares with them. The most important of them would be: offering of specific services based on the appointment of events (with open or reserved access); trying to provide the public and participants with new and useful experiences; targeting a wide audience; regularity in support of certain programs; choosing specific topics for the target audience, etc. In addition, we have not to overlook that the hub is an environment that promotes finding new opportunities for offering specific products to a more educated, more aware, more active and involved audience, who wants to multiply and transmit and share their experiences to others. The cultural hub - as a social and economic phenomenon - differs from other forms of hubs (cultural centres, cultural platforms, idea incubators, clusters, etc.) by a few specific features. Based on this new skills and competences are formed \& next developed for the personnel activating within the museum structures, so that it can cope with the new cultural management methods and add value to the museum presence in the life of the whole local community.

If these soft skills are added along with communication and relationship with third parties, acquired in the process of prefacing the museum into a cultural hub, we can already speak of a conceptual redefinition of the Romanian museum assumed pragmatically. Some authors (Falk, 2009) consider that by analysing some examples of museums that are already considered cultural hubs, we might be able to ascertain the museum potential. The purpose of transforming the museum by revaluating partnerships and relationships with stakeholders is that the museum institution can continue to play its fundamental role and, at the same time in can actively support creativity and innovation, even outside a purely cultural area. Collaboration between museums and art galleries through marketing initiatives and by creating a cultural hub that can share a common vision might help them broaden and diversifying their audience. (Kutay, 2016).

Considering the multiple benefits of implementing the cultural hub vision in Romania, we may record a national progress in terms of opening museums to host multidisciplinary events covering many diverse topics. Thus, some of Romanian museums might be considered as true cultural hubs, confirmed and recognized as such not only by specialists, but also by a wide category of public. Alongside the institutional perspective focused on the cultural positive impact on the public and the internal human resources, which might benefit from the guidance of a strategic oriented management, another major influence is the potential ability of the museum to develop partnerships with other institutions, which will allow it to offer to the public various programs capable of truly enhancing the social and economic impact of the cultural heritage held, even more so that year 2018 was the European Year of Cultural Heritage. Another 
important factor is the regularity of scheduling events under the patronage of the museum that will get the public used to participate in new and diverse high quality experiences. In return, varied and inventive programs need not only adequate infrastructure, but also constant funding (including new financing tools such as crowdsourcing platforms), because through the economic contribution they bring to the tourism industry, museums have a significant impact not only on the socio-economic level, but also in the transformation of cultural consumption habits. A mandatory step in the process of transforming museums in cultural hubs is the opening of these institutions to various cultural events, which will enrich the cultural offerings within a community. As museums will organize more interesting activities for people, their condition and purpose will be closer to those of true cultural centres, cultural platforms or cultural hubs, with a very important role in preserving the cultural heritage and the sustainable cultural development of the community.

We consider that another mandatory step in ensuring the success of such an innovative process is the integration of such a management strategy into a general urban regeneration plan, to be dedicated to the recognition and promotion of cultural diversity, in order to achieve the deepest social inclusion, especially within urban agglomerations. The specialists in the museum field have concluded that cities including the smart city vision become community spaces centred on culture, as a way to make their own identity more visible. Therefore, it is considered that the cultural hub is a potential vector capable of protecting the urban cultural heritage in all its forms.

The idea of improving the quality of public spaces through culture, successfully taken over by cultural hubs, offers museums not only the possibility of a new cultural approach based on creativity, in order to encourage social inclusion, but also the chance of an active participation in the regeneration of cities through a creative revaluation of cultural heritage. Therefore, a compulsory stage in the transformation of the museum in a cultural hub is the awareness of the public about the usefulness and necessity of going through this process and of the need to connect it to the cultural acts from anywhere expressed in the same way. Already the web presence is a "must have" for each museum institution, regardless of the form of ownership or the nature of its heritage. These technologies can be used both outside and inside the museum: as a teaching environment, as a means of outward projection (the virtual as a means of communication) or as a museum environment itself.

\section{Methodology}

Our research is mostly an initial desk research based largely on the investigation of the relevant reference, web statistics analysis and on examples of best practices.

In the next paragraphs we will analyse the Museum as a Cultural hub and its Internet visitors on their collaborative platforms. Unlike previous researches that analysed the behaviour of online visitors mainly by applying questionnaires, conducting interviews and direct observation of a group of users, the present paper proposes to use a less popular method, but whose main advantages are low costs, accessibility and the high representativeness of the data, as well as the lack of need to interact directly with the users. Given these advantages, web statistics analysis is the first step that a museum has to take in order to understand the online visitor behaviour. Such an analysis allows the formation of a general image regarding the preferences of the visitors, the interest expressed by them to explore the content of the website, the attention paid to the different pages and correspondingly to the quality of the content published on the site.

Although it has many potential benefits, this method also has some limitations related to obtaining qualitative data, in particular, to identify the causes that led to the appearance of a certain behaviour by visitors. Even if some of these causes can be easily assumed, without interacting with online visitors it is quite difficult to identify all the issues that affect the quality 
of the website. For this reason, it is recommended that the initial analysis of the visitation behaviour based on the web statistics have to be followed by conducting more in-depth studies based on the direct observation of a group of users or by application of questionnaires as quantitative method.

\section{Results \& Analysis}

Online presence is an attribute of implementing the latest information technologies, in the attempt to adapt the museum institutions to a constantly changing world. There are many technologies that can facilitate the contact between the public and the cultural heritage and they might help reinventing the museum institutions and turn them into real cultural hubs and platforms to support more dialogue.

To become more attractive and profitable, museums around the world have begun to use digital media, multimedia and smartphone applications. Thus, the information can be presented in a more attractive way, without neglecting the educational aspect. Audio guides, digital assistants, tablets and information points, all competing in fulfilling the educational role of modern museums, by attracting people connected to the latest technologies. They help the visitors in their interpretation and better understanding of the exhibits.

Many cultural institutions, especially museums, manage vast collections of heritage pieces. The artefacts can be degraded, in time, in case of improper storage conditions, and also because of their exposure in rooms that do not always meet the optimal conditions of conservation. To avoid such situations, cultural institutions can use modern digitization technologies. With the help of 3D scanners, museums around the world have begun to create digital versions of artefacts and monuments. Some of them can be found on the Digital European Library site (The European Library). Large objects and even an entire archaeological complex can be digitized. One way to do this is to use drones to take numerous pictures, based on which 3D models are made. Regardless of the method chosen for the creation of 3D models, they must be carefully designed and processed for future use. In addition, besides the availability of digital materials, it would be useful for dedicated mobile applications to provide information about available museums and cultural routes, resulting in a complete guided tour of the patrimony. 3D printers can create highly accurate replicas of artefacts, which can be used in traveling exhibitions or offered as souvenirs. We can see as a fact confirmed that the construction of 3D virtual models allows the design of a new form of communication through which the archaeological objects become accessible elements for different users, being valid products for both the specialist in the field and for a wider audience. We should try to investigate a variety of services offered by museums: answers to questions, availability of images in the collection, guide experience, relevance of the collection, the possibility of photography, various facilities such as parking, toilets, cafe, banks, photo frames etc. The study of visitors must be more complex and also to go beyond the analyse the relationship between the visitor and the museum's products.

We consider that, in addition we should study the empirical behaviour of visiting, as well as the educational, emotional or therapeutic effects of it, but also the exploring process in relation with other cultural practices. Visitor studies are not limited to those undertaken by museums, but also include: academic research, government statistics, leisure industry or the arts community research. In this context, it is necessary that the study of the public of a particular museum has to be corroborated not only with demographic data of the general population, but also with other studies of visitors or cultural consumption, in order to know the larger context in which we are located. Digital technology has allowed the fragmentation of the masses, which have been consolidated over time, since the spread of agriculture and the creation of large cities. If a visitor is forced to visit with the school or a group, his personal interests will not come to light, but if it is an event in which he can explore freely, then external motivation 
may be beneficial. Traditional marketing was particularly concerned with the external motivation of the client, while relational marketing seeks to maximize the internal ones through external motivations.

In order to be able to attract this audience with different tastes and with certain reservations, museums have to stimulate the accessibility steps by: changing the presentation mode, introducing new technologies (which are already a part of daily life) and changing the distribution of cultural products (they can be consumed online or in public spaces such as those in front of the museum, but also in malls and markets). Understanding the existing patterns in visitor behaviour is also a management tool through which museums can maximize the social and cultural experience offered to visitors. Also, by analysing the visiting behaviour and the impact that the museographic layout of an exhibition space (appearance, density of exhibited objects, methods of communication and exposure used) has on the satisfaction felt by the visitors is essential to evaluate the performance of the products and services offered by museums. Although there is much research focused on examining the behaviour and motivation of visitors within museums, the category of virtual visitors is less analysed compared to that of physical visitors.

At the same time, besides the fact that there is little research dedicated to studying the online visitors of museums, the methods of collecting and interpreting the data used are not adapted to the particularities of different museums. Thus, while the large national and international museums allow themselves to allocate funds for the creation of websites by specialized companies or to employ qualified personnel in this field, many small and medium museums have developed their websites with the help of its own employees, not specialized in web programming, and without having a special budget allocated for this.

Websites allow museums to provide access to their digital collections and online exhibitions to wider and more diverse user groups and to provide additional information for individuals who have visited the museum. Therefore, to increase the degree of dissemination of information on cultural heritage it is not enough for museums to have a website, but the resources they offer online must be accessible and easy to use. For this reason, it is essential to take users and their needs into account for easy interaction with the online content published by the museum.

Knowing the characteristics and patterns of behaviour of virtual visitors might help museums to evaluate the degree in which their websites are relevant, useful and meet the goals for which they were created. At the same time, studying the search for information behaviour of online users is essential for museums to create websites that meet the needs of their visitors to the greatest extent. Research carried out so far has shown that the website of a museum is very likely to be accessed by users who show significant differences both in terms of the motivation behind the visit and the level of education, studies and knowledge of museum collections and exhibitions. Thus, among the most important reasons for visiting the site of a museum are: obtaining information for planning a future visit (program, rates, etc.); finding specific information about a particular content, either for professional or personal interest; occasional navigation, without looking for anything specific; and conducting a transaction on the site (purchase of tickets or souvenirs / publications from a museum's online store).

Depending on these reasons, the virtual visitors of the museums can be structured in three main categories, as follows: the general visitor, who looks for program information, rates, exhibitions and facilities offered by the museum; the educational visitor, who, in addition to the general visitor, seeks more detailed information in order to plan the visit; and the specialist visitor, who is additionally interested in previous categories and detailed information on museum collections. Therefore, due to the fact that different categories of users have different goals and needs when accessing digital collections, museums have to take into account a wide variety of requirements when designing the content and structure of websites. 
Given the major importance of knowing the characteristics and behaviour of online visitors in designing a successful website, several recent studies have focused on researching aspects such as: the needs and expectations of online museum visitors before and after a physical visit within the museum; strategies used by various user groups to search for information; visitors' opinions on how to present the content published on the site; the experience of using the website and the intention to pay a physical visit to the museum; the reasons for accessing the online collections offered by the museum, as well as how users interact with these collections. Although through direct observation, focus group and interviews, as qualitative methods used in order to obtain data that allow to improve the functionality of the website and optimize the way of organizing information, these methods are expensive, require a high volume of human resources and work, and the collected data might have a subjective character. However, these quantitative data are significant for the overall assessment of the degree to which a museum's website corresponds to the needs of the users. Another advantage of the data collected through web statistics is that it does not require direct contact with online visitors and, as a result, does not determine the risk of influencing their interaction with the content published on the site. Therefore, we believe that any attempt to analyse the behaviour of online visitors made in order to improve the quality of the website of a museum should have as a starting point the recording and interpretation of the statistical data of the site. At the same time, since many small and medium-sized museums have created websites with very little time, money and expertise, or even without a specific budget for website development and maintenance, it is unlikely that they will use costly tools to understand the characteristics and needs of online visitors.

\section{Conclusions}

By highlighting the characteristics of museums that have begun their transformation in cultural hubs and following the analysis of some influencing factors and the mandatory stages that must be completed, we consider that we can design some recommendations.

Firstly, as Romanian museum specialists draw attention, it is necessary to carry out a systematic analysis, based on a clear methodology, to monitor the degree in which the main indigenous museums have the potential to become cultural hubs. In addition, museum specialists must be kept up to date with the news in this domain by organizing regular knowledge exchanges and consulting meetings with specialists from similar institutions, but also from other types of establishments.

These should not only be limited to professional networking, but should also be extended to wider experience exchanges, including with economic actors, potential investors and with as many stakeholders as possible. Therefore, the change to the status of cultural hub forces the museum to a transformation that can only be a good omen for all involved. Approaching such a strategy, with the characteristic notes of its own profile, the museum becomes a dynamic factor in the development of a wide range of cultural services, which bring even more welfare to a community and, perhaps the most important thing, once it has become cultural hub, the museum can actively contribute to civic education and to the increase of social cohesion - these are deficient aspects whose improvement should concern as many responsible factors in society as possible. The technological advance allows the opening of new avenues of exploration and knowledge of the historical-archaeological heritage. Exiting the museums from the "comfort state" and adopting, alongside the adaptation, the new computer technologies will enhance the value of the heritage held. Thus, new groups of visitors can be targeted, new ways of knowing or new cultural routes can be identified or created.

All in all, we can clearly state that collaborative internet platforms can bring financial benefits and popularity for a large variety of places. Maybe that is the reason why a lot of cultural hubs keep in touch with their potential visitors online. Coupons, discounts or simply 
announcements of new events are starting to become more efficient on making tourists curious than the traditional methods.

We consider that, in the future, the power of social media have to be used wisely by the people in charge of the promotion of cultural tourism attractions. While on one hand it might bring a level of success unimaginable a couple of years before, it can also bring people that might not valuate enough the cultural product they are consuming. It is within this context of enormous growth potential, and increasing pressure on tourism infrastructure and services, that travel \& tourism competitiveness can be seen simultaneously as a powerful economic growth driver or a risk to ongoing development of the industry if not managed correctly.

\section{References}

Becut, A. M. (2018). Perceptiile populatiei privind patrimoniul cultural material si imaterial in Studiul de consum cultural la nivelul orasului. Bucuresti.

Eid, H. A. (2015). The Museum Innovation Model: a museum perspective on open innovation, social enterprise and social innovation. Retrieved from

https://www.researchgate.net/publication/329884894_The_Museum_Innovation_Mod el_A_museum_perspective_on_innovation.

ECTC-European cultural tourism network (2019). Awards 2019 Edition Overall Theme: Culture and Heritage for Responsible Innovative and Sustainable Tourism Actions. Retrieved from http://www.culturaltourism-network.eu/award-2019.html.

Falk, J. (2009). Identity and the Museum Visitor Experience. Walnut Creek: Left Coast Press. Kutay, G. (2016). Simulating visitor behaviuor. Cambridge.

Muzeele ca platforme culturale, in "Muzee" nr.1/2019, Institutul National de Formare si Cercetare Culturala, Cultura-Data.ro

The European Library. History of the European Library. Retrieved from https://www.europeana.eu/portal/en/TEL.html.

The Travel \& Tourism Competitiveness Report (2019) Travel \& Tourism Competitiveness Index. Retrieved from http://reports.weforum.org/pdf/ttci-

2019/WEF_TTCI_2019_Profile_ESP.pdf; http://reports.weforum.org/travel-andtourism-competitiveness-report-2019/rankings/.

United Nations World Tourism Organization. (2019). accesed on 10th January 2020

World Tourism Organization. (2019). International Tourist Highlights 